\title{
NOTES ON ALMOST-PERIODICITY \\ IN TOPOLOGICAL VECTOR SPACES
}

\section{GASTON MANDATA N'GUÉRÉKATA}

Faculte des Sciences

Universite de Bangui

BF 1450 BANGUI

Repubiique Centrafricaine

(Received December 27, 1983)

ABSTRACT. A study is made of almost-periodic functions in topological vector spaces with applications to abstract differential equations.

KEY WORDS AND PHRASES. TOpological vector spaces, abstract differential equations. 1980 MATHEMATICS SUBJECT CLASSIFICATION CODE. 34 G10

1. INTRODUCTION.

In our recent papers [1, 2], we extended the theory of almost-periodic functions from Banach spaces to topological vector spaces ana gave a few results concerning its applications to abstract differential equations. The following results are the continuation of discussions begun there. Specifically Theorem 2 is a version of a theorem contained in [1,2] (see Theorem 5.1 in [2]) which was originally inspired from a result due to A. I. Perov (cf. [3] Theorem 1.1).

Let us first recall some useful facts (see [1,2] for more details). The reader can also find in [4] the elementary properties of linear topological spaces needed here.

DEFINITION 1. A continuous function $f: R+E$, where $E$ is a complete locally convex space and $R$ is the set of real numbers, is called almost periodic (a.p.) if for each neighborhood (of the origin in $E$ ) $U$, there exists a real number $\ell=\ell(U)>0$ such that every interval $[a, a+\ell]$ contains at least a point $\tau$ such that

$$
f(t+\tau)-f(t) \in U \text { for every } t \in R \text {. }
$$

$\tau$ is theri called a $U$-translation number of the function $f$.

REMARK: $U=U\left(\varepsilon ; p_{j}, \Lambda \leq i \leq n\right)$

$$
=\left\{x \in E ;{ }_{i} p(x)<\varepsilon, 1 \leq i \leq n\right\}
$$

where each $p_{i} \in Q$, the set of semi-norms on $E$.

Finally we recall Bochner's criteria: If $E$ is a Frechet space, then a function $f: F \rightarrow E$ is a.p. iff for every real sequence $\left(s_{n}^{1}\right)_{n=1}^{\infty}$ there exists a subsequence $\left(s_{n}\right)_{n=1}^{\infty}$ such that $\left(f\left(t+s_{m}\right)\right)_{n=1}^{\infty}$ converges uniformly in $t \varepsilon R$.

DEFINITION 2. A Frechet space $E$ is called a perfect Frechet space if the following property is verified ir. $E$ : every function $\phi: R \rightarrow E$ such that 
(i) $\{\phi(t) ; t \varepsilon R\}$ is bounded in $E$

(ii) the derivative $\phi^{\prime}(t)$ is a.p. in $E$, is necessarily a.p. in $E$.

2. MAIN RESULTS.

Now let us state and prove:

THEOREM 1. If $f(t)$ is a.p. in a complete locally convex space $t$, then for every real sequence $\left(s_{n}\right)_{n=1}^{\infty}$ there exists a subsequence $\left(s_{n}^{\prime}\right)_{n=1}^{\infty}$ such that for every neighborhood (of the origin in $E$ ) $U$,

$$
f\left(t+s_{n}^{\prime}\right)-f\left(t+s_{m}^{\prime}\right) \varepsilon U
$$

for all t $\varepsilon R, m$ and $n$.

PROOF. Let $U=U\left(\varepsilon ; p_{j}, 1 \leq i \leq n\right)$ be a neighborhood and $V=V\left(\frac{\varepsilon}{4} ; p_{j}, 1 \leq i \leq n\right)$ a symmetric neighborhocd such that $V+V+V+V \quad U$. By the definition of almostperiodicity, there exists $\ell=\ell(V)$ (therefore $\ell$ depends on $U$ ) such that in every real interval of length $\ell$, there exists $\tau$ such that

$$
f(t+\tau)-f(t) \varepsilon V
$$

for every $t \in R$.

Now for each $s_{n}$, we can find $\tau_{n}$ and $\sigma_{n}$ such that $s_{n}=\tau_{n}+\sigma_{n}$ with $\tau_{n}$ a $v$-translation number of $f$ and $\sigma_{n} \varepsilon[0, l]$ (it suffices to take $\tau_{n} \varepsilon\left[s_{n}-\ell, s_{n}\right]$ and then $\left.\sigma_{n}=s_{n}-\tau_{n}\right)$.

As $f$ is uniformly continuous on $\operatorname{R}(c f .[1,2])$, there exists $\delta=\delta(\varepsilon)$ such that

$$
f\left(t^{\prime}\right)-f\left(t^{\prime \prime}\right) \varepsilon V
$$

for all $t^{\prime}, t^{\prime \prime},\left|t^{\prime}-t^{\prime \prime}\right|<2 \delta$.

Also $0 \leq \sigma_{n} \leq \ell$ for every $n$; we can then subtract from $\left(\sigma_{n}\right)_{n=1}^{\infty}$, a convergent subsequence $\left(\sigma_{n_{k}}\right)_{k=1}^{\infty}$, by the Bolzano-Weierstrass theorem.

Let $\sigma=\lim _{k \rightarrow \infty} \sigma_{n_{k}}$, with $0 \leq \sigma \leq \ell$.

Now consider the subsequence $\left(\sigma_{n_{k}}\right)_{k=1}^{\infty}$ with

$$
\sigma-\delta<\sigma_{n_{k}}<\sigma+\delta, k=1,2, \ldots
$$

and let $\left(s_{n_{k}}\right)_{k=1}^{\infty}$ be the corresponding subsequence where

$$
s_{n_{k}}=\tau_{n_{k}}+\sigma_{n_{k}}, k=1,2, \ldots
$$

Let us prove the relation

for all $t \in R$.

$$
f\left(t+s_{n_{k}}\right)-f\left(t+s_{n_{j}}\right) \varepsilon U
$$

For this, write

$$
\begin{aligned}
f\left(t+s_{n_{k}}\right)-f\left(t+s_{n_{j}}\right)=f(t & \left.+\tau_{n_{k}}+\sigma_{n_{k}}\right)-f\left(t+\sigma_{n_{k}}\right) \\
& +f\left(t+\sigma_{n_{k}}\right)-f\left(t+\sigma_{n_{j}} !\right. \\
& +f\left(t+\sigma_{n_{j}}\right)-f\left(t+\tau_{n_{j}}+\sigma_{n_{j}}\right) .
\end{aligned}
$$

Because $\tau_{n_{k}}$ and $\tau_{n_{j}}$ are V-translation numbers of $f$, we shall get 


$$
\begin{aligned}
& f\left(t+\tau_{n_{k}}+\sigma_{n_{k}}\right)-f\left(t+\sigma_{r_{1}}\right) \varepsilon v, \text { for every } t \in R \\
& f\left(t+\tau_{n_{j}}+\sigma_{n_{j}}\right)-f\left(t+\sigma_{n_{j}}\right) \varepsilon v, \text { for every } t \varepsilon R .
\end{aligned}
$$

On the other hand

$$
\left|\left(t+\sigma_{n_{k}}\right)-\left(t+\sigma_{n_{j}}\right)\right|=\left|\sigma_{n_{k}}-\sigma_{n_{j}}\right|<2 \delta ;
$$

therefore, by usir.g relaticn (2.1), we get

$$
f\left(t+o_{n_{k}}\right)-f\left(t+o_{n_{j}}\right) \in V \text {, for every } t \in R .
$$

Finally we can deduce (2.2) from (2.3) and (2.4). The theorem is proved by takirig

$$
s_{n}^{\prime}=s_{n_{k}}, k=1,2, \ldots
$$

\section{APPLICATIONS}

Let $E$ be a perfect Frechet space and $A$ a closed linear operator with domain $D(A)$ dense in $E$. Suppose $A$ generates a strongly continuous one-parameter group $T(t), t \in R$.

Consider in such $E$ the differential equation

$$
x^{\prime}(t)=A x(t), \quad t \in R \text {. }
$$

THEOREM 2. Assurie for every semi-norm $p \in Q$, there exists a semi-norm $q \varepsilon Q$ such that

for every $u \in E$ and $t \in R$.

$$
p(T(t) u) \leq q(u)
$$

Then every solution $x(t)$ of (3.1) such that $\left\{x^{\prime}(t) ; t \in R\right\}$ is relatively compact in $E$ is a.p.

PROOF. Let $x(t)$ be such a solution; we can write $x(t)=T(t) x(0), t \varepsilon R$; by the property on $T(t), x(t)$ is obviously bounded.

Consider a given real sequence $\left(s_{n}^{\prime}\right)_{n=1}^{\infty}$; we can extract a subsequence $\left(s_{n}\right)_{n=1}^{\infty}$ such that $\left(x^{\prime}\left(s_{n}\right)\right)_{n=1}^{\infty}$ is a Cauchy sequence in $E$, for $\left\{x^{\prime}(t) ; t \varepsilon R\right\}$ is relatively compact in $E$. We have

$$
\begin{aligned}
x^{\prime}\left(t+s_{n}\right) & =A x\left(t+s_{n}\right) \\
& =\operatorname{AT}\left(t+s_{n}\right) \times(0) \\
& =\operatorname{AT}(t) T\left(s_{n}\right) \times(0) \\
& =\operatorname{AT}(t) \times\left(s_{n}\right) \\
& =T(t) A x\left(s_{n}\right) \\
& =T(t) x^{\prime}\left(s_{n}\right)
\end{aligned}
$$

for every $n$ and every $t \in R$. Therefore

$$
x^{\prime}\left(t+s_{n}\right)-x^{\prime}\left(t+s_{m}\right)=T(t)\left[x^{\prime}\left(s_{n}\right)-x^{\prime}\left(s_{m}\right)\right]
$$

for every $n, m$ and $t \in R$.

Take now any $p \in Q$; then there exists $q \in Q$ such that

$$
p\left[x^{\prime}\left(t+s_{n}\right)-x^{\prime}\left(t+s_{m}\right)\right] \leq q\left[x^{\prime}\left(s_{n}\right)-x^{\prime}\left(s_{m}\right)\right]
$$

for every $t \in R$; which shows $x^{\prime}(t)$ is a.p. by Bochner's criteria. As $E$ is a perfect Frechet space, the conclusion is inmediate. 
The author was supported by a Fulbright grant at the University of California at Berkeley trom June to Cctober 1983.

\section{REFERENCES}

1. N'GUÉRÉKATA, G. M. Remarques sur les Équations Differentielles Abstraites, These de Ph.D., Universite de Montreal, Juin 1980.

2. N'GUÉRÉKATA, G. M. Almost-Periodicity in Linear Topological Spaces and Applications to Abstract Differentia? Equations, Internat. $\therefore$. Math. Math. Sci. 7 (1984) 529-540.

3. ZAIDMAN, S. Solutions Presque-Periodiques des Équations Differentielles Abstrai tes, Enseign. Math. 24 (1978), 87-110.

4. ROBERTSON, A. P. and ROBERTSCN, W. Topological Vector Spaces, Cambridge University Press, 1973.

5. AMERIO, L. and PROUSE, G. Almost-Periodic Furictions and Functional Equations, Van Nostrand, 1971.

6. CORDUNEANU, C. Almost-Periodic Functions, Interscience, 1968. 


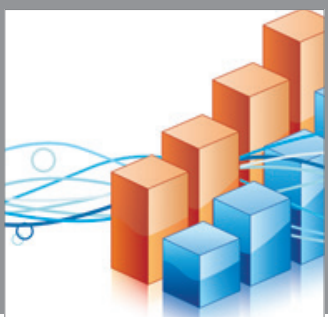

Advances in

Operations Research

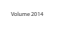

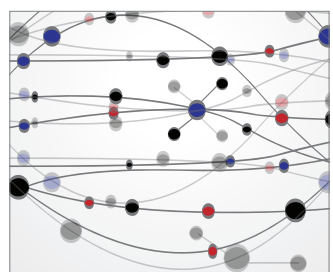

\section{The Scientific} World Journal
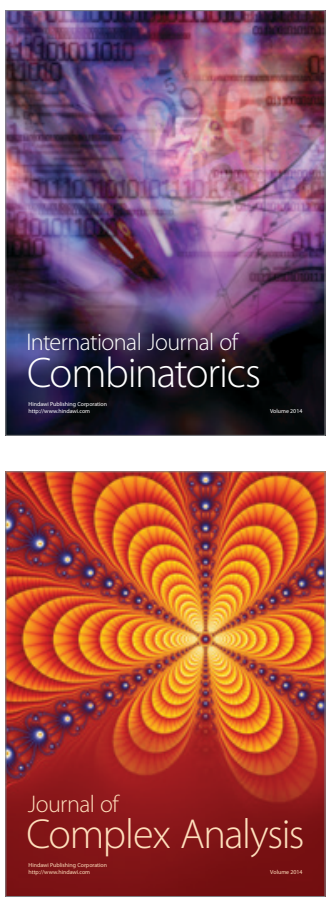

International Journal of

Mathematics and

Mathematical

Sciences
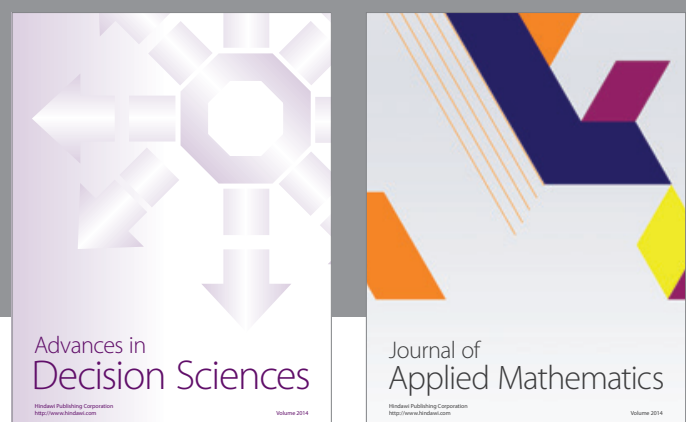

Journal of

Applied Mathematics
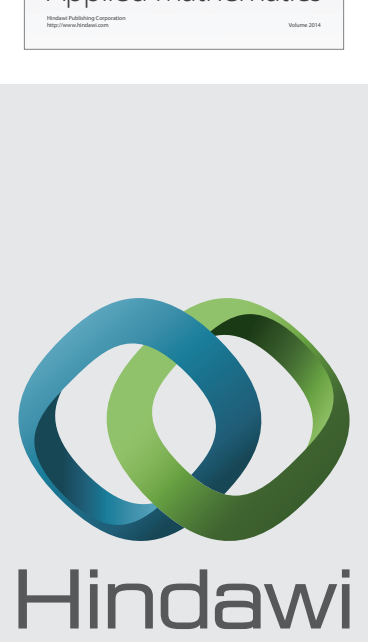

Submit your manuscripts at http://www.hindawi.com
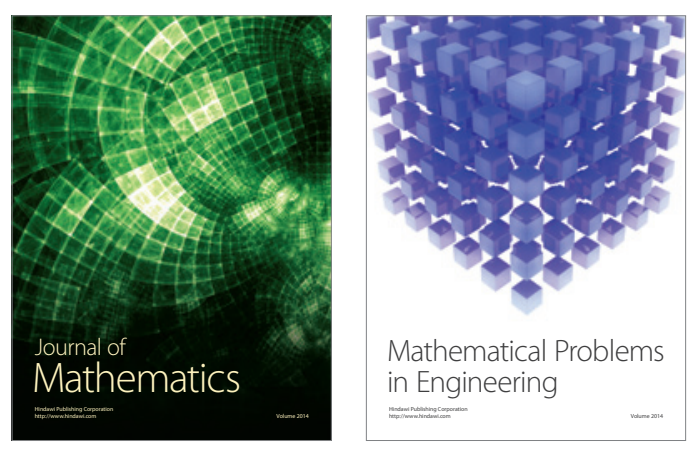

Mathematical Problems in Engineering
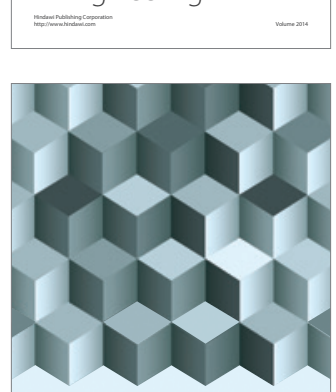

Journal of

Function Spaces
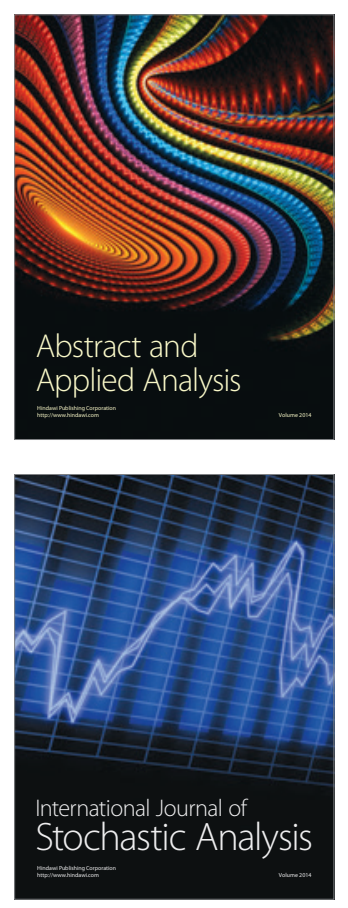

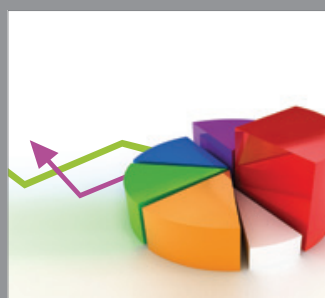

ournal of

Probability and Statistics

Promensencen
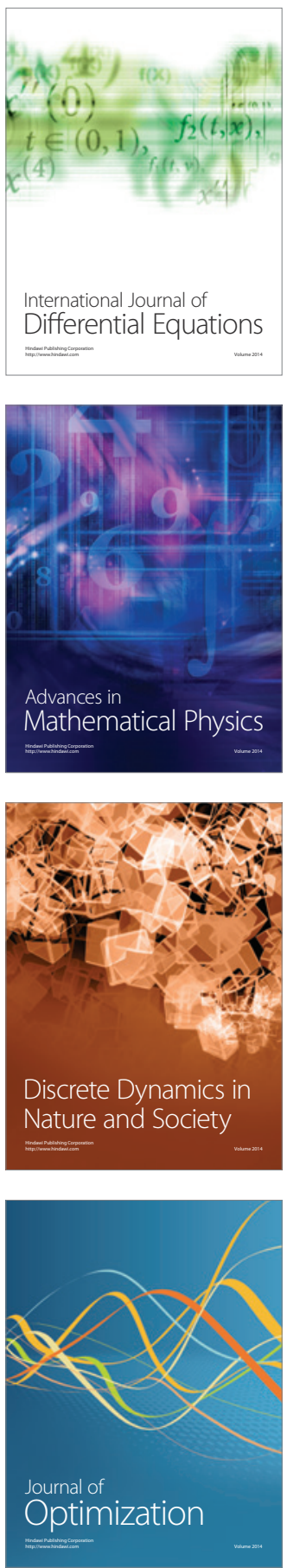